\title{
Research on the Application of Energy Internet Big Data in Integrated Energy Market
}

\author{
Wenyu Zhou \\ Institute of Quantitative \& Technical Economics, Chinese Academy of Social Sciences, Beijing, China \\ Email: zhouwyu@qq.com
}

How to cite this paper: Zhou, W.Y. (2017) Research on the Application of Energy Internet Big Data in Integrated Energy Market. Energy and Power Engineering, 9, 328335.

https://doi.org/10.4236/epe.2017.94B038

Received: February 20, 2017

Accepted: March 30, 2017

Published: April 6, 2017

\begin{abstract}
Energy Internet is deeply integrated by Internet concept, information technology and energy industry, and Energy Internet Big Data are one of core technologies that achieve energy-information-economic interconnection and improve the development and evolution of Energy Internet. This paper describes the concept and characteristics of Energy Internet Big Data, and feasibility of applying Energy Internet Big Data to integrated energy market. On this basis, as for integrated energy market and multi-subjects of Energy Internet, typical application and technical system based on Energy Internet Big Data in integrated energy market is put forward, which provides a reference for the analysis and decision of integrated energy market in Energy Internet.
\end{abstract}

\section{Keywords}

Energy Internet, Energy Internet Big Data, Integrated Energy Market, Data Mining

\section{Introduction}

Energy Internet is a new comprehensive intelligent energy system, which aims at the development of high efficient green energy, and integrates the Internet information technology, "long-distance, large capacity" energy transmission technology and new renewable energy sources. The State Council of China proposed the guidance on promoting "Internet plus" action in July 2015, in which "Internet plus wisdom energy" was classified as one of the key programs [1]. National Energy Administration issued the guidance on promoting the development of 'Internet plus wisdom energy' in February 2016, and notification on organizing demonstration projects of Energy Internet in July, which promoted the implementing of demonstration projects [2] [3].

In the context of Energy Internet, energy market will no longer be limited to 
price competition. It is critical to develop value-added services that face to energy production, circulation, consumption and other chains based on big data innovation. Meanwhile, the development of energy big data service application is one of ten key tasks involved in the guidance on promoting the development of "Internet plus wisdom energy" [2]. Energy Internet Big Data is not only the progress of technology, but also relates to the major change of integrated energy system in development concept, management system and technology during the era of big data. Overall, Energy Internet Big Data is the form of value in the era of big data leap of the next generation of smart energy systems.

\section{Energy Internet and Big Data}

\subsection{Energy Internet}

Energy Internet is new development form of energy system deeply integrated by Internet, energy production, transmission, storage, consumption and energy market. In the aim of achieving maximum utilization of energy, Energy Interne will achieve multi-energy complementation and source-network-load-storage coordination in the process of energy production, transmission, storage and consumption, and contribute to energy efficiency improvement, environment-friendly and sustainable development of mankind through the interaction among energy flow, information flow and value flow [4]. Moreover, Energy Internet is a complex physical energy system with multiple energy interconnection characterized by multi-energy complementation, source-network-load-storage coordination and information-physics coupling, and it is a complex economic system as well, which is divided into three levels logically: physics, information and economic.

\subsection{Energy Internet Big Data}

Big data refer to data set that is unable to capture, manage, and process by conventional tools and massive and diversified information assets that has stronger power on decision-making, insight and optimization only in a new processing model, which characterized by volume, velocity, variety, value and veracity [5].

Energy Internet is a complex system which is formed by the integration of energy system, information communication system and economic system, and a big data system composed of internal and external data as well. Big Data in Energy Internet is an important hub connecting the physical and economic level, and also play a key role in process of energy-information coupling. Meanwhile, unique function and importance of Big Data in Energy Internet is determined by characteristics of Energy Internet such as open, peer to peer, interconnect sharing [6] [7].

1) Realization of collaborative optimization of multi subjects in Energy Internet.

2) Achievement of safe, stable and economic operation of Energy Internet.

3) Formation of business model in Energy Internet. 
4) Improvement of control and management level in Energy Internet.

\section{Feasibility Analysis of the Application of Energy Internet Big Data in Integrated Energy Market}

Energy production and consumption, energy market, marketing and management will affect energy economy, policy formulation and economic decisionmaking. Meanwhile, they are also influenced by external links such as social economic conditions and policies. The emergence of new market subjects in Energy Internet, such as virtual power plants, load integrators, third party value-added service providers, greatly increases the flexibility of resource supply. Accordingly, it is necessary to improve the market mechanism, compatible with channels that users can participate in independent market transaction of flexible resource in direct or indirect ways and establish a reasonable pricing mechanism of flexible resource compensation to ensure a reasonable return on flexible resource investment. However, current information system is basically limited to the business layer of energy production and dispatching. It is quite difficult to promote the interaction with energy and information among energy production, transmission, storage and consumption, promote intelligent charging and discharging business, encourage users to participate in power demand response, provide flexible energy service independently such as energy response, frequency modulation and peak shaving, achieve collaborative optimization of various energy sources and real time transaction based on Internet platform.

Big data is a combination of the classic market theory and innovative data-driven methods, which is integrated with information theory and behavior in the analysis and decision-making. So that the interaction between macro and micro decision-making becomes more rapid and efficient. Based on marketing data in customer service system, user information collection system, marketing business system and so on, it is critical to mine behavior characteristics of market participants, evaluate customer credit, analyze potential energy alternatives, forecast energy market risks, develop competitive strategies, support more flexible transactions, prompt participants to adopt the quantitative paradigm and decision-making mechanism, excavate commercial value in the field of e-commerce and energy conservation services.

\section{Typical Application Based on Energy Internet Big Data in Integrated Energy Market}

Energy Internet Big Data are not just a kind of specialized technology that some technical aspects of the energy industry need, but also cornerstone of the entire Energy Internet technology. Multi-subjects compete in integrated energy market. Subject that meets the needs of customers will grasp the initiative of market. The development of big data services oriented energy end users is the key factors to win customers and grasp dominance of market. The application of Energy Internet Big Data will cover all aspects of customer energy consumption behavior analysis, energy balance, demand response, market transaction and social 
service [8] [9].

\subsection{Customer Energy Consumption Behavior Analysis}

1) User Energy Efficiency Management

Energy systems are managed automatically, efficiently and scientifically in process of energy data collection, process control, energy consumption analysis of medium and energy management through centralized monitoring and control, which can combine energy management with energy production and energy consumption organically and improve the overall level of energy management. Based on energy production data, comprehensive production information data in manufacturing execution system and data of enterprise resource planning, cost of sales and energy business daily management information, system of energy production is analyzed and managed by data processing and analysis technology.

2) Customer Focus Analysis

Analysis of customer focus based on big data will help improve customer service, business event monitoring and job scheduling, which allows site managers to understand customers focus quickly. Managers will grasp dynamic of the service, adjust coping strategies accordingly, optimize service resources, and improve the service and management from the customers' concern through the analysis of customer focus.

3) Payment Channel Analysis

Except for traditional payment channels such as energy company business hall, collection outlets of financial institutions and collection outlets non-financial institutions, there are many new payment channels appearing such as mobile phone application, WeChat, Alipay etc. Based on the big data analysis technology, relationship model between payment channel and cost recovery time, amount, customer type is established. Managers can determine how to optimize layout and management of payment channels by big data.

\subsection{Energy Balance, Demand Response and Market Transactions}

1) Energy Balance

Optimal operation mode and load control plan are determined by comprehensive analysis of energy consumption of users, energy prices of different regions and time, weather forecast and heating characteristics while users are guided by reasonable price structure power and gas to transfer load and flat the load curve. Based on Energy Internet Big Data, long-term goal of energy saving and environment protecting is achieved through optimizing production operation mode of power and other energy companies, improving consumption of intermittent renewable energy, and guiding the concept of energy saving and emission reduction.

2) Demand Response

It is important to integrate a variety of data of energy production, transportation, sales, management, simulate the process of demand side response, analyze 
the proportion of regional energy demand, sort out the various factors that influence demand side response, find out the best objects to carry out demand side response and form simulation model in the end. Based on simulation model, the optimal response strategy is determined by adjusting the proportion of different types of enterprises and residents in demand side response.

3) Market Transactions

The market of Energy Internet is characterized by multi-subjects, standardization of commodity, intelligent logistics, and multilateral trade liberalization. Through user behavior analysis and user market segmentation with a large amount of energy production and consumption data, energy enterprises can optimize marketing organization and improve the service mode accordingly. Meanwhile, decision makers can be provided intuitive, multi-dimensional, comprehensive and in-depth forecast data and grasp the market dynamics through data exchange with the outside world, miming relationship between energy consumption and energy prices, weather, traffic and other hidden factors.

\subsection{Social Service}

1) Macroeconomic Analysis Supporting Policies

Based on a large amount of data to power enterprises, algorithms of clustering, classification, neural network are applied to analyze energy features of enterprise including peak periods, power factor, power quality, and enterprise network power flow stability. Meanwhile, based on a large number of energy consumption data of enterprises and residents, local governments can carry out regional macroeconomic analysis such as conditions of electricity consumption, electric charge and electric fluctuation, electricity proportion in various industries and so on, which will help governments understand the economic situation in the region, anticipate the short-term trend of economic development in the area and constitute policy that suit for local development through a series of simulation parameters.

2) Supporting Energy Efficiency Decision

To find out existing problems of energy consumption in enterprises, energy consumption data are collected, analyzed and mined in real time by means of energy efficiency terminal in enterprise energy management and big data models. So that power and government agencies can grasp the situation of energy companies, understand actual level of regional energy consumption, adjust enterprise energy management policies and technical standards to forecast the changing trend of regional energy consumption level and making reasonable policies and regulations supporting power grid and government agencies.

\section{Technical System Based on Energy Internet Big Data in Integrated Energy Market}

By means of data statistics, machine learning, data mining, domain knowledge mining and data visualization, distribution, relationships, trends, patterns, laws and even properties hidden in Energy Internet Big Data can be apperceived and 
exhibited. So users' individual energy demand, energy consumption characteristics of different users and spatial distribution characteristics of energy network loss can be learned to promote user interaction, demand management, energy prediction, intelligent energy, network loss reduction, as well as users' private use of energy options and other services [10].

The application of Big Data in Energy Internet can be divided into five parts: data collection, data cleaning, data integration, data mining, data interpretation and application. Data cleaning and data integration is the premise of data mining and data interpretation. Data mining and data interpretation and application closely link to each other, which help users apperceive and control big data with deep insight and multi-dimension. Technical system of big data is shown in Figure 1.

1) Data Collection

In Energy Internet, smart micro-grid control and management system, energy trading and service system and smart energy management service system is the main source of data for analysis and mining on Energy Internet Big Data. Data are collected automatically by intelligent micro energy network information acquisition system. The distributed sensor network is used to collect the data and transmit the collected data to the distributed data storage system.

2) Data Cleaning

Data cleaning is to eliminate noisy data, including the process of eliminating duplicate data, filling missing data, correcting abnormal data and so on. Abnormal data are detected by filtering technology and smoothed by estimating parameter of noisy data while missing data are complemented by interpolation technology.

3) Data Integration

Energy Internet Big Data are related to energy supply, transmission, consumption, control and management and other aspects of chains. To solve the problem of distribution and heterogeneity of big data, data are exchanged and shared through data integration.

4) Data Mining

In Energy Internet, energy flow, information flow and value flow integrate and interact deeply. Because of its openness, equality, equity and sharing, supervised learning algorithm cannot meet the decision-making need of multi subjects in Energy Internet. Big data mining algorithm is one kind of intelligent algorithm of unsupervised learning, which will learn automatically without manual

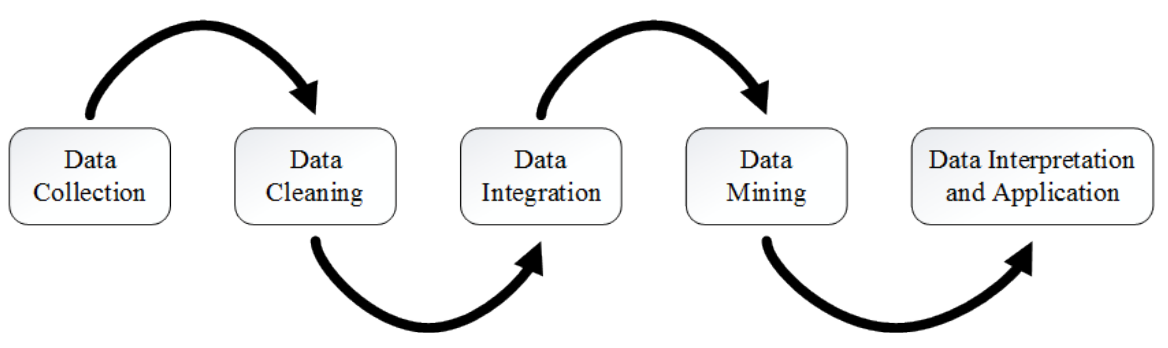

Figure 1. Technical system of big data. 
setting and pre-training. Big data diming technology includes classification, clustering, association, etc. Main algorithms of big data mining are shown in

Table 1.

5) Data Interpretation and Application

The result of big data diming is filtered, purified, interpreted and changed into semantic form that can be understood. With deep excavation of needs and values of multi-subjects in Energy Internet, the result can be applied to the actual work and operation of Energy Internet finally.

\section{Concluding Remarks}

In view of the new generation of energy system "Energy Internet", this paper analyze the significance and feasibility of Energy Internet Big Data, discuss typical application based on Energy Internet Big Data in integrated energy market such as customer energy consumption behavior analysis, energy balance, demand response, market transaction and social service, put forward technical system based on Energy Internet Big Data in integrated energy market. This provides a scientific and reasonable information support for multi-subjects in Energy Internet to explore the potential commercial value, analyze decisionmaking in energy market and formulate services and marketing strategies.

Table 1. Main algorithms of big data mining.

\begin{tabular}{|c|c|}
\hline Algorithm Category & Algorithm Name \\
\hline \multirow{6}{*}{ Classification } & Logistic Regression \\
\hline & Bayesian \\
\hline & SVM \\
\hline & Perceptron \\
\hline & Neural Network \\
\hline & Random Forests \\
\hline \multirow{8}{*}{ Clustering } & Restricted Boltzmann Machines \\
\hline & Canopy Clustering \\
\hline & K-means Clustering \\
\hline & Fuzzy K-means \\
\hline & Expectation Maximization \\
\hline & Mean Shift Clustering \\
\hline & Hierarchical Clustering \\
\hline & Spectral Clustering \\
\hline Association & Parallel FP Growth Algorithm \\
\hline Regression & Locally Weighted Linear Regression \\
\hline \multirow{4}{*}{ Dimension Reduction } & Singular Value Decomposition \\
\hline & Principal Components Analysis \\
\hline & Independent Component Analysis \\
\hline & Gaussian Discriminative Analysis \\
\hline
\end{tabular}




\section{Acknowledgements}

Thanks to financial aid sponsored by Beijing Social Science Fund, as well as guidance and assistance that units and individuals provide during the research work.

\section{References}

[1] (2015) The State Council of the People's Republic of China's Guidance on Promoting "Internet plus" Action. [2015-08-23]. (In Chinese) http://www.gov.cn/zhengce/content/2015-07/04/content_10002.htm

[2] (2016) Guidance on Promoting the Development of "Internet plus" Smart Energy. [2016-02-24]. (In Chinese) http://www.ndrc.gov.cn/zcfb/zcfbtz/201602/t20160229_790900.html

[3] (2016) National Energy Administration's notification on Organization and Implementation of "Internet plus" Smart Energy (Energy Internet) Demonstration Projects. National Energy Administration, 2016-07-26. (In Chinese)

[4] Huang, A.Q., Crow, M.L., Heydt, G.T., et al. (2011) The Future Renewable Electric Energy Delivery and Management (FREEDM) System: The Energy Internet. Proceedings of the IEEE, 99, 133-148. https://doi.org/10.1109/JPROC.2010.2081330

[5] Choi, T.-M., Chan, H.-K. and Yue, X.H. (2017) Recent Development in Big Data Analytics for Business Operations and Risk Management. IEEE Transactions on Cybernetics, 47, 81-92. https://doi.org/10.1109/TCYB.2015.2507599

[6] Jaradat, M., Jarrah, M., Bousselham, A., et al. (2015) The Internet of Energy: Smart Sensor Networks and Big Data Management for Smart Grid. Procedia Computer Science, 56, 592-597. https://doi.org/10.1016/j.procs.2015.07.250

[7] Dong, C.Y., Zhao, J.H., Wen, F.H., et al. (2014) From Smart Grid to Energy Internet: Basic Concept and Research Framework. Automation of Electric Power Systems, 38, 1-11. (In Chinese)

[8] Xue, Y.S. and Lai, Y.N. (2016) Integration of Macro Energy Thinking and Big Data Thinking (Part One): Big Data and Power Big Data. Automation of Electric Power Systems, 1, 1-8. (In Chinese)

[9] Xue, Y.S. and Lai, Y.N. (2016) Integration of Macro Energy Thinking and Big Data Thinking (Part Two): Applications and Explorations. Automation of Electric Power Systems, 8, 1-13. (In Chinese)

[10] Cao, J.W., Yuan, Z.D., Ming, Y.Y. and Zhang, H.Y. (2015) Survey of Big Data Analysis Technology for Energy Internet. Southern Power System Technology, 11, 1-12. (In Chinese) 
Submit or recommend next manuscript to SCIRP and we will provide best service for you:

Accepting pre-submission inquiries through Email, Facebook, LinkedIn, Twitter, etc. A wide selection of journals (inclusive of 9 subjects, more than 200 journals)

Providing 24-hour high-quality service

User-friendly online submission system

Fair and swift peer-review system

Efficient typesetting and proofreading procedure

Display of the result of downloads and visits, as well as the number of cited articles Maximum dissemination of your research work

Submit your manuscript at: http://papersubmission.scirp.org/

Or contact epe@scirp.org 